\title{
Large Cell Neuroendocrine Carcinoma Arising from the Left Main Bronchus
}

\author{
Hirokazu Tokuyasu ${ }^{1}$, Yasuto Sakaguchi ${ }^{2}$, Noritaka Isowa ${ }^{2}$, Hiroki Izumi ${ }^{1}$, Kenichi Takeda ${ }^{1}$, \\ Hiroshi Miura ${ }^{3}$ and Eiji Shimizu ${ }^{4}$
}

\begin{abstract}
A 67-year-old man was referred to our hospital for a detailed medical examination of a bronchial polyp that was detected during chest computed tomography. Bronchoscopic examination revealed a tumor that almost occluded the main left bronchus. Nd-YAG laser treatment and tumor removal with biopsy forceps were conducted. On the basis of the histopathological and immunohistochemical features, large cell neuroendocrine carcinoma (LCNEC), T2aN0M0, stage IB was diagnosed. After induction chemotherapy with a combination of cisplatin and etoposide, a sleeve resection of the left main bronchus with telescoping bronchial anastomosis was performed. LCNEC typically occurs in the peripheral lung field, but here, we report a rare case of LCNEC arising from the left main bronchus.
\end{abstract}

Key words: large cell neuroendocrine carcinoma, main bronchus

(Intern Med 50: 2003-2006, 2011)

(DOI: 10.2169/internalmedicine.50.5526)

\section{Introduction}

In 1991, Travis et al proposed a new category of large cell neuroendocrine carcinoma (LCNEC) (1). The revised World Health Organization (WHO) International Histological Classification of lung tumors considers LCNEC a subtype of large cell carcinoma (2). Though LCNEC typically occurs in the peripheral lung field, we encountered a rare case of LCNEC arising from the left main bronchus.

\section{Case Report}

A 67-year-old man was referred to our hospital for a detailed medical examination of a bronchial polyp that was detected during chest computed tomography (CT). The patient was a non-smoker, and the levels of the lung cancer markers carcinoembryonic antigen, cytokeratin 19 fragment, and progastrin-releasing peptide were all within normal limits. A chest CT scan showed an endobronchial tumor of diameter $2 \mathrm{~cm}$ at the proximal part of the left main bronchus (Fig. 1).
Bronchoscopic examination showed that the tumor almost occluded the left main bronchus (Fig. 2). One month later, the patient underwent Nd-YAG laser treatment, and tumor removal using biopsy forceps was performed, consequently $90 \%$ of the right main bronchus was opened. Histologically, the tumor showed solid growth patterns including trabeculae and pseudorosettes (Fig. 3). Further, focal necrosis was seen, and at a higher magnification, the neoplastic cells showed an abundant amphophilic cytoplasm, moderately pleomorphic nuclei, and finely granular chromatin. A mitotic rate of up to 20 mitoses per 10 high-power fields (HPF) was noted. In immunoperoxidase studies, the neoplastic cells were found to be positive for synaptophysin (Fig. 3). On the basis of the histopathological and immunohistochemical features, atypical carcinoid and non small cell lung carcinoma with neuroendocrine features was ruled out and LCNEC, T2aNOM0, stage IB was diagnosed. The patient received 2 courses of chemotherapy consisting of intravenous cisplatin $\left(80 \mathrm{mg} / \mathrm{m}^{2}\right.$, day 1$)$ and etoposide $\left(100 \mathrm{mg} / \mathrm{m}^{2}\right.$, days $\left.1-3\right)$. A second bronchoscopic examination revealed an irregular protuberant lesion without endobronchial tumor regrowth. 18-

\footnotetext{
${ }^{1}$ Division of Respiratory Medicine, Matsue Red Cross Hospital, Japan, ${ }^{2}$ Division of Thoracic Surgery, Matsue Red Cross Hospital, Japan, ${ }^{3}$ Division of Pathology, Matsue Red Cross Hospital, Japan and ${ }^{4}$ Division of Medical Oncology and Molecular Respirology, Department of Multidisciplinary Internal Medicine, Faculty of Medicine, Tottori University, Japan
}

Received for publication March 18, 2011; Accepted for publication May 30, 2011

Correspondence to Dr. Hirokazu Tokuyasu, tokuun3200@yahoo.co.jp 

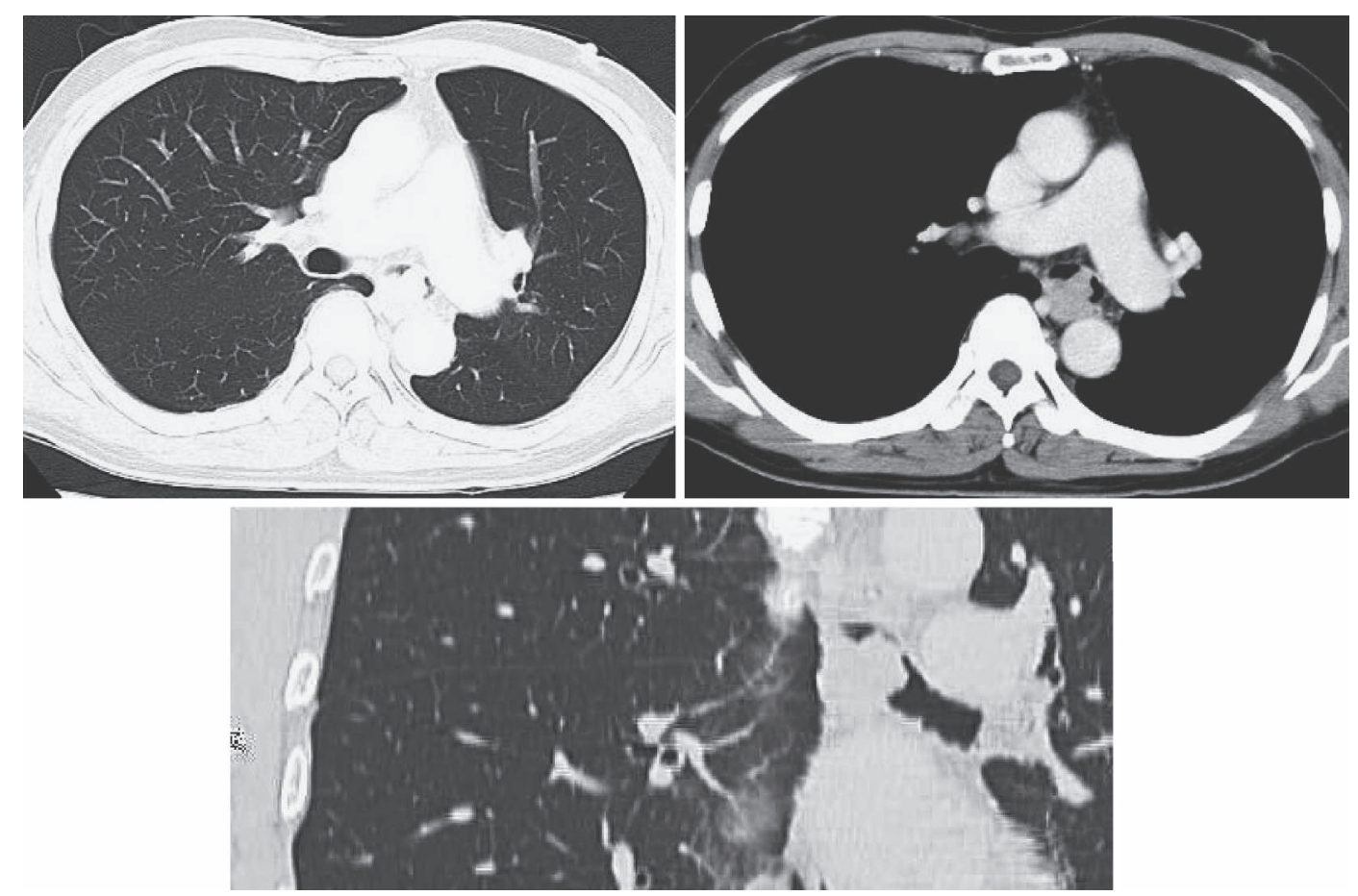

Figure 1. Chest CT scan showing an endobronchial tumor of diameter $2 \mathrm{~cm}$ at the proximal part of the left main bronchus.
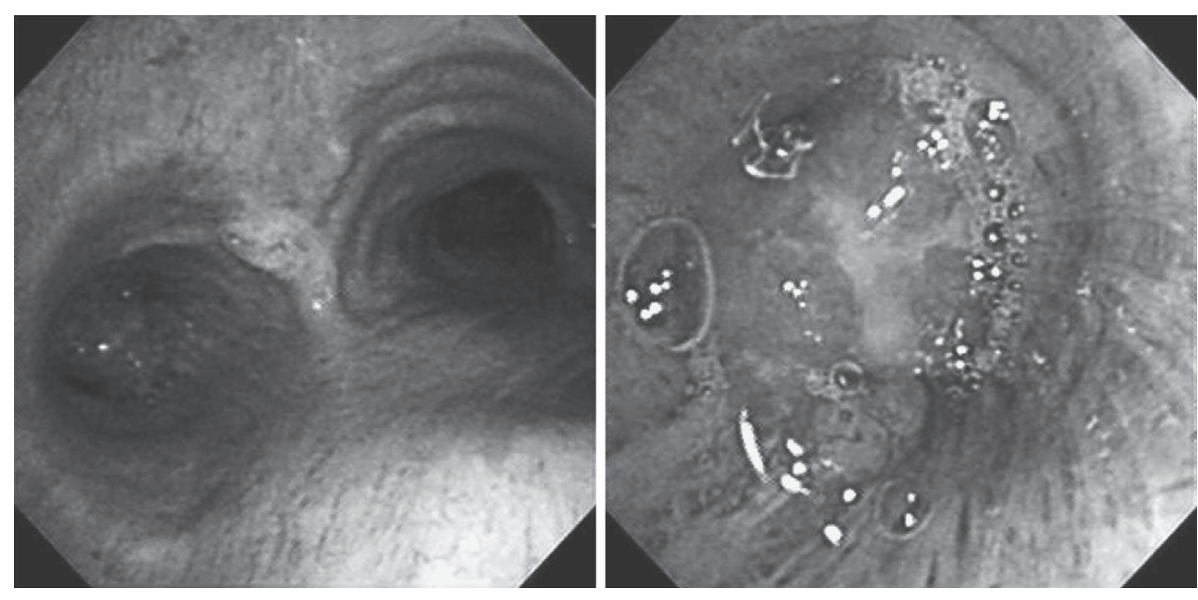

Figure 2. Bronchoscopic examination showing a tumor that almost occluded the main left bronchus.

Fluorodeoxyglucose-positron emission tomography (FDGPET) conducted before and after chemotherapy demonstrated FDG activity in the left bronchus tumor, and maximum standardized uptake value had attenuated from 11.42 to 4.48 after the 2 sessions. Four months after the first visit, a sleeve resection of the left main bronchus with telescoping bronchial anastomosis was performed. Currently, 9 months after the surgery, the patient is alive with no relapse.

\section{Discussion}

Pulmonary neuroendocrine tumors arise from Kulchitsky cells, which are normally present in the bronchial mucosa $(3,4)$. These tumors are classified into 4 subtypes on the basis of clinicopathological, morphological, and biological features: typical carcinoid and atypical carcinoid are low- to intermediate-grade malignant tumors, whereas LCNEC and small cell carcinoma are high-grade malignant tumors (1). The revised WHO International Histological Classification of lung tumors considers LCNEC as a subtype of large-cell carcinoma (2). The histological criteria of LCNEC proposed by the WHO in 1999 were as follows (5): 1) a tumor with neuroendocrine morphological features (organoid nesting, palisading, rosettes, and trabeculae); 2) a high mitotic rate of $\geq 11$ mitoses per $2 \mathrm{~mm}^{2}$; 3) necrosis (often in large zones); and 4) cytological features of nonsmall cell carcinoma (NSCLC), i.e., large cell size, low nuclear/cytoplasmic ratio, vesicular or fine chromatin, and/or 

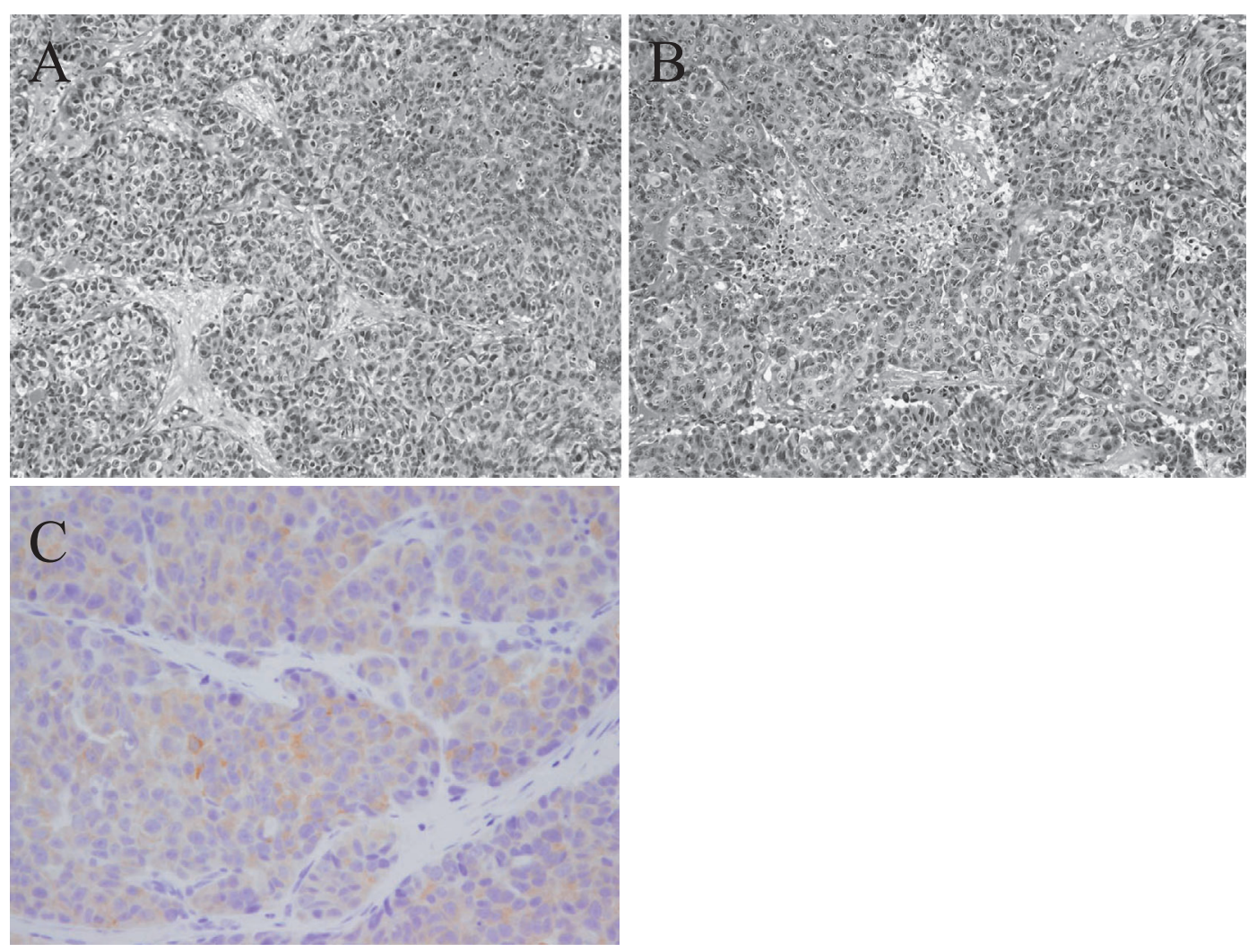

Figure 3. (A) The tumor cells are large and polygonal, have a low nuclear-cytoplasmic ratio and are arranged in trabeculae and pseudorosettes. (B) Low magnification view showing central necrosis. (C) Immunohistochemical examination showing positive staining for synaptophysin.

frequent nucleoli. By definition, LCNECs are positive for 1 or more neuroendocrine markers such as chromogranin, synaptophysin, and neural-cell-adhesion-molecule, as assessed by immunohistochemistry, or they contain neuroendocrine granules as detected by electron microscopy.

LCNEC has a reported prevalence of $2.87 \%$ (22 of 766) or $3.1 \%$ (87 of 2790 ) in surgically resected lung cancers $(6,7), 18.5 \%$ (37 of 200) in pulmonary neuroendocrine tumors (8), and $12 \%$ in all large cell undifferentiated carcinomas (9). Thus, the incidence of LCNEC as compared to other types of primary lung cancers appears to be around $3 \%$, so it is considered to be comparatively rare. The development of these tumors is closely related to a positive smoking history. In the study conducted by Travis et al (1), all 5 patients were heavy smokers. However, in another study, 4 out of the 11 cases of LCNEC occurred in nonsmokers (10). Moreover, the incidence of the tumors increases with age, and they are more common among men; the frequency of LCNEC in men is 4 times that in women (7).

The CT findings of LCNEC are nonspecific and similar to other non-small -cell lung cancers. Usually, the nodules and masses occur peripherally and have a well-defined and lobulated appearance, but they may also have a spiculated margin. In a series of 21 LCNEC patients, 6 had chest pain, 5 were asymptomatic, 4 manifested cough or hemoptysis, and 6 had nonspecific presentations including flu-like symptoms, dyspnea, and night sweats (11). To our knowledge, only 1 case of endobronchial LCNEC has been reported (12). In that report, several similarities with an atypical carcinoid were pointed out, such as well-developed neuroendocrine morphology, endobronchial location of the tumor, no smoking history, and an effective clinical therapy, which were similar to the features observed in our case. However, the tumor in the present patient differs from an atypical carcinoid tumor because of its high mitotic rate and morphology and from small cell carcinoma because of its cytological features.

Patients with LCNEC often present with advanced disease at diagnosis. One study staged LCNEC in 87 patients and found the following results: IA, 23\%; IB, 24\%; IIA, 3\%; IIB, 12\%, IIIA, 20\%; IIIB, 15\%; and IV, 3\% (7). A published surgical series report mentions that the 5-year survival for overall and stage I LCNEC is $21.2-57 \%$ and $27-67 \%$, respectively $(7,13,14)$. Even patients with tumors diagnosed at an early stage do not have a good prognosis. There is not much information on chemotherapy for LCNEC, and surgery alone is not the optimal treatment measure for LCNEC; further, the effect of combined treatment modalities for LCNEC patients has not yet been determined. Yamazaki et al reported that in 20 LCNEC cases, the objective response rate of chemotherapy with cisplatin was $50 \%$ (15). Veronesi et al reported that a clinical response to induction chemotherapy was observed in 12 (11 partial and 1 complete response) of 15 patients, i.e., the response rate was $80 \%$ (13). In the present case, induction chemotherapy with a combina- 
tion of cisplatin and etoposide was very effective, as evaluated by FDG-PET and bronchoscopic examination.

The authors state that they have no Conflict of Interest (COI).

\section{References}

1. Travis WD, Linnoila RI, Tsokos MG, et al. Neuroendocrine tumors of the lung with proposed criteria for large cell neuroendocrine carcinoma. An ultrastructural, immunohistochemical, and flow cytometric study of 35 cases. Am J Surg Pathol 15: 529-553, 1991.

2. World Health Organization Classification of Tumours. Travis WD, Brambilla E, Muller-Hermelink HK, et al, Eds. Tumours of the Lung, Pleura, Thymus and Heart: Pathology and Genetics. International Agency for Research on Cancer Press, Lyon, France, 2004.

3. Mller NL, Miller RR. Neuroendocrine carcinomas of the lung. Semin Roentgenol 25: 96-104, 1990.

4. Sheppard MN. Neuroendocrine differentiation in lung tumors. Thorax 46: 843-850, 1991.

5. Travis WD, Colby TV, Corrin B, Shimosato Y, Brambilla E. Histological Typing of Lung and Pleural Tumours. 3rd ed. Springer, Berlin, 1999.

6. Jiang SX, Kameya T, Shoji M, Dobashi Y, Shinada J, Yoshimura $\mathrm{H}$. Large cell neuroendocrine carcinoma of the lung: a histologic and immunohistochemical study of 22 cases. Am J Surg Pathol 22: 526-537, 1998.

7. Takei H, Asamura H, Maeshima A, et al. Large cell neuroendo- crine carcinoma of the lung: a clinicopathologic study of eightyseven cases. J Thorac Cardiovasc Surg 124: 285-292, 2002.

8. Travis WD, Rush W, Flieder DB, et al. Survival analysis of 200 pulmonary neuroendocrine tumors with clarification of criteria for a typical carcinoid and its separation from typical carcinoid. Am J Surg Pathol 22: 934-944, 1998.

9. Hammond ME, Sause WT. Large cell neuroendocrine tumors of the lung: clinical significance and histopathologic definition. Cancer 56: 1624-1629, 1985.

10. Jung KJ, Lee KS, Han J, et al. Large cell neuroendocrine carcinoma of the lung: clinical, CT, and pathologic findings in 11 patients. J Thorac Imaging 16: 156-162, 2001.

11. Zacharias J, Nicholson AG, Ladas GP, Goldstraw P. Large cell neuroendocrine carcinoma and large cell carcinoma with neuroendocrine morphology of the lung: prognosis after complete resection and systemic nodal dissection. Ann Thorac Surg 75: 348-352, 2003.

12. Megyesi M, Berta M, Khoor A. Endobronchial large cell neuroendocrine carcinoma. Pathol Oncol Res 9: 198-200, 2003.

13. Veronesi G, Morandi U, Alloisio M, et al. Large cell neuroendocrine carcinoma of the lung: a retrospective analysis of 144 surgical cases. Lung Cancer 53: 111-115, 2006.

14. Paci M, Cavazza A, Annessi V, et al. Large cell neuroendocrine carcinoma of the lung: a 10-year clinicopathologic retrospective study. Ann Thorac Surg 77: 1163-1167, 2004.

15. Yamazaki S, Sekine I, Matsuno Y, et al. Clinical responses of large cell neuroendocrine carcinoma of the lung to cisplatin-based chemotherapy. Lung Cancer 49: 217-223, 2005.

(C) 2011 The Japanese Society of Internal Medicine http://www.naika.or.jp/imindex.html 